\title{
Mathematical Modeling of Epicardial RF Ablation of Atrial Tissue with Overlying Epicardial Fat
}

\author{
Ana González Suárez ${ }^{1}$, Fernando Hornero² and Enrique J. Berjano*,1 \\ ${ }^{I}$ Institute for Research and Innovation on Bioengineering (I3BH), Universidad Politécnica de Valencia,Valencia, Spain \\ ${ }^{2}$ Department of Cardiac Surgery, Hospital General Universitario, Valencia, Spain
}

\begin{abstract}
The efficacy of treating atrial fibrillation by RF ablation on the epicardial surface is currently under question due to the presence of epicardial adipose tissue interposed between the ablation electrode and target site (atrial wall). The problem is probably caused by the electrical conductivity of the fat $(0.02 \mathrm{~S} / \mathrm{m})$ being lower than that of the atrial tissue (0.4-0.6 S/m). Since our objective is to improve epicardial RF ablation techniques, we planned a study based on a twodimensional mathematical model including an active electrode, a fragment of epicardial fat over a fragment of atrial tissue, and a section of atrium with circulating blood. Different procedures for applying RF power were studied, such as varying the frequency, using a cooled instead of a dry electrode, and different modes of controlling RF power (constant current, temperature and voltage) for different values of epicardial fat thickness. In general, the results showed that the epicardial fat layer seriously impedes the passage of RF current, thus reducing the effectiveness of atrial wall RF ablation.
\end{abstract}

\section{INTRODUCTION}

Radiofrequency (RF) currents have been employed in many surgical and therapeutic procedures, such as atrial fibrillation (AF), a common arrhythmia and a significant public health problem for its clinical prevalence and morbidmortality. The prevalence of AF increases with age and reaches almost $5 \%$ of the population over 69 and $8 \%$ of those over 80 [1]. Data from the Framingham heart study show that $\mathrm{AF}$ is associated with a 1.5 to 1.9 -fold higher death risk and may be associated with thromboembolic stroke $[2,3]$.

The use of surgical ablation for atrial fibrillation (AF) is on the increase in spite of the lack of knowledge of the mechanisms involved. The atrial myocardium needs to be ablated in order to restore sinus rhythm. The effectiveness of surgical ablation in this intervention is $70-80 \%$ independent of the kind of energy used [4-6]. Early post-ablation recurrence of the arrhythmia probably depends on lesion transmurality [7], and the existence of epicardial fat [8]. Histological analysis of surgical lesions has shown $25-30 \%$ non transmurals lesions [9-11].

The efficacy of standard RF ablation on the epicardial surface is uncertain due to the varying presence of epicardial adipose tissue interposed between the ablation electrode and target site, i.e. the atrial wall (see Fig. 1) [12,13]. This is probably caused by the electrical conductivity of the fat $(0.02 \mathrm{~S} / \mathrm{m})$ being lower than that of atrial tissue $(0.4-0.6$ $\mathrm{S} / \mathrm{m})$.

In order to achieve optimum epicardial ablation of atrial tissue under a layer of fat, different types of energy are currently being researched, such as high intensity focused

*Address correspondence to this author at the Departamento de Ingenieria Electronica (7F), Universidad Politecnica de Valencia, Valencia, Spain; E-mail: eberjano@eln.upv.es ultrasound (HIFU) [14], microwave [15], laser [12] and cryoablation [16]. As we considered that this issue has not been sufficiently studied, we designed a computer modeling study of the effect of different electrode designs and protocols for delivering RF power [17] to assess the capacity of different techniques to ablate atrial tissue in the presence of epicardial fat. We first studied the effect of using different frequencies with a standard $4 \mathrm{~mm} 7$-Fr electrode. A previous experimental study had reported that a frequency of $2 \mathrm{MHz}$ resulted in a $22 \%$ increase in lesion depth when compared to a frequency of $100 \mathrm{kHz}$ [18]. We then assessed the effect of the RF ablation mode (voltage, current and temperature constant). Finally, taking into account that previous experimental studies have shown that an internally cooled electrode (also known as a cooled-tip electrode) can generate epicardial lesions more efficiently than standard electrodes in zones with overlying epicardial fat [19], we also included this kind of electrode in the study.

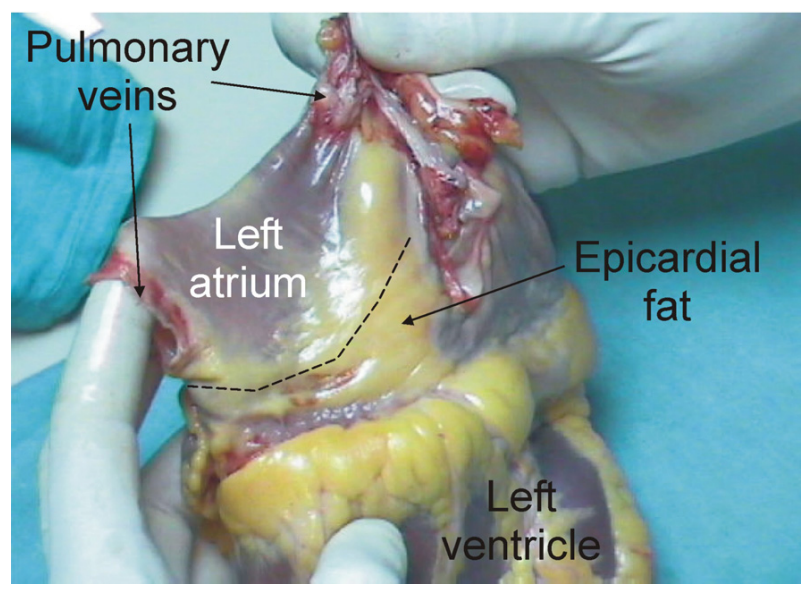

Fig. (1). Explanted heart in which the presence of epicardial fat can be noted on left atrium. Dashed line represents a possible ablation line. 


\section{METHODS}

\section{Description of the Theoretical Model}

Although different RF electrode geometries have been proposed for epicardial RF ablation of atrial tissue [13,20], we simplified the physical situation of the study by using a 4 $\mathrm{mm}$ long active electrode with a 3-mm-diameter hemispherical tip. The electrode contacted the tissue at an angle of $90^{\circ}$ and hence presented axisymmetric characteristics and a two-dimensional approach could be used. Fig. (2) shows the proposed theoretical model, which shows the active (stainless steel) electrode with a section of plastic (polyurethane) probe, a fragment of epicardial fat over a fragment of atrial tissue, and a section of atrium with circulating blood. The active electrode is inserted in the fat layer to a depth of $1.5 \mathrm{~mm}$ (corresponding to the electrode radius). The value of the model parameters $\mathrm{Z}$ and $\mathrm{R}$ were calculated by means of a sensitivity analysis in order to avoid boundary effects.

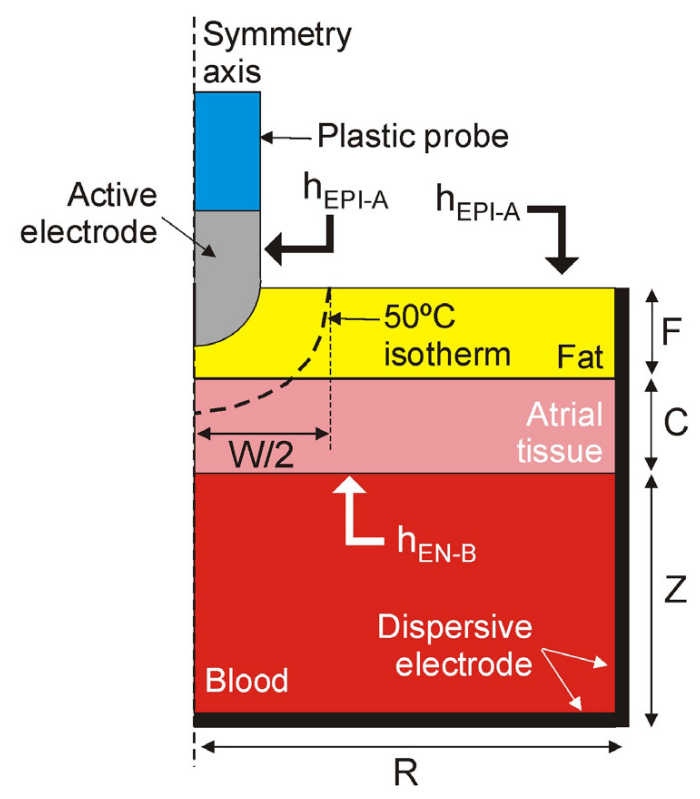

Fig. (2). Two-dimensional theoretical model proposed (out of scale). Z and R: outer dimensions of the model; $\mathrm{C}$ : atrial wall thickness; F: epicardial fat thickness. $h_{\text {EPI-A }}$ is the thermal transfer coefficient at the epicardium-ambient and electrode-ambient interfaces, while $h_{\mathrm{EN}-\mathrm{B}}$ is the thermal transfer coefficient at the endocardium-blood interface. Depth (D) and width (W) of the lesion were assessed using the $50^{\circ} \mathrm{C}$ isotherm.

\section{Governing Equations}

Temperature $(T)$ in the tissue was obtained by solving the Bioheat Equation, which governs thermal phenomena during therapeutic heating of biological tissues:

$\rho \cdot c \cdot \frac{\partial T}{\partial t}=\nabla \cdot(k \nabla T)+q-Q_{p}+Q_{m}$

where $\rho, c$ and $k$ are respectively the density, specific heat and thermal conductivity of the tissue. The term $Q_{p}$ corresponds with the heat loss caused by blood perfusion; and $Q_{m}$ models the metabolic heat generation. This last term is always ignored in RF ablation modeling since it has been shown to be insignificant. It has also been shown that the $Q_{p}$ term can be ignored in the case of cardiac ablation [21]. Finally, $q$ is the heat source generated by RF power. In RF ablation, this term is related with electrical power density $P$ $\left(\mathrm{W} / \mathrm{m}^{3}\right)$, which is in general a complex number given by [22]:

$$
P=(\sigma+j \omega \varepsilon)|E|^{2}
$$

where $\sigma$ is electrical conductivity $(\mathrm{S} / \mathrm{m}), \varepsilon$ is permittivity $(\mathrm{F} / \mathrm{m})$, and $|E|$ is the magnitude of the vector electric field (V/m). The value of this vector is evaluated from $\vec{E}=-\nabla \Phi$ where $\Phi$ is the voltage $(\mathrm{V})$. The voltage is obtained by using Laplace's equation:

$\nabla \cdot \sigma \nabla \Phi=0$

Only the real part of power density, i.e. $\operatorname{Re}\{P\}$ contributes to the heating of the tissue, i.e. $\operatorname{Re}\{P\}=q$. However, the permittivity has in fact a real (non-dissipative) and an imaginary (dissipative) part, i.e. $\varepsilon=\varepsilon^{\prime}-j \varepsilon^{\prime}$. Consequently:

$q=\operatorname{Re}\{P\}=\left(\sigma+\omega \varepsilon^{\prime \prime}\right) \cdot|E|^{2}$

where $\omega$ is angular frequency $\left(\mathrm{s}^{-1}\right)$. The term $\sigma \cdot|E|^{2}$ represents the heat resulting from dissipation due to convection currents (translational motion of ions), while the term $\omega \varepsilon^{\prime \prime} \cdot|E|^{2}$ represents the heat from dissipation due to irreversible rotation and vibration of bound charge carriers [22].

At the ablation frequencies considered in this study (100$10,000 \mathrm{kHz}$ ) and over the distance of interest (electrical power is deposited within a small radius around the active electrode) the biological medium can be considered totally resistive since the displacement currents can be neglected. A quasistatic approach was therefore possible to solve the electrical problem [23].

The ANSYS program (ANSYS, Canonsburg, PA, USA) was used for the creation of Finite Element Models (FEM) and for solving the above equations by computer simulations. We used the PLANE67 elements (linear isoparametric type), which allow the coupled thermalelectric problem to be solved, where the electrical problem involves a DC (direct-current) problem. This means that the electrical variables in the model (voltage and current) are DC values, and hence they correspond with the root-mean-square value of the RF signal.

\section{CHARACTERISTICS OF MODEL ELEMENTS}

Table 1 shows the thermal and electrical characteristics of the model elements. In order to model the use of different frequencies, we considered the values of electrical conductivity reported in the literature for three frequencies: $100 \mathrm{kHz}, 1 \mathrm{MHz}$, and $10 \mathrm{MHz}$. Although a previous modeling study on hepatic RF ablation considered a frequency value of $10 \mathrm{kHz}$ [24], this value is too low for RF cardiac ablation, due to the possibility of electrical stimulation. In fact, in an experimental study, a $20 \mathrm{kHz}$ current induced ventricular fibrillation [18]. Since no difference between $\sigma$ and $\varepsilon$ " is made in the literature, we 
assume that the value of reported electrical conductivity includes both mentioned phenomena, and hence corresponds with an effective value $\sigma_{\text {effective }}=\sigma+\omega \varepsilon^{\prime \prime}$. In addition, we considered a change of $+2 \% /{ }^{\circ} \mathrm{C}$. The values shown in Table $\mathbf{1}$ are effective values $[8,25]$. In order to assess the effect of the epicardial fat layer on each ablation mode and electrode design, our study considered four values of fat thickness between 2 and $5 \mathrm{~mm}$. The thickness of the atrial wall was considered to be fixed at $3 \mathrm{~mm}$.

\section{Boundary and Initial Conditions}

In all FEM problems the boundary conditions must be defined. Regarding the electrical boundary conditions, null electrical current (Neumann boundary condition) was used at the symmetry axis, and also on the tissue-ambient and device-ambient interfaces. The electrical boundary conditions on the active and dispersive electrodes depend on the ablation mode considered and hence are described in the following section.

Regarding thermal boundary conditions, null thermal flux was used at the symmetry axis (Neumann boundary condition). The temperature values of surfaces at a distance from the active electrode were fixed by using Dirichlet boundary conditions. We assumed a value of $20^{\circ} \mathrm{C}$ in the upper limit of the probe and $36^{\circ} \mathrm{C}$ on the dispersive electrodes (see Fig. 2).

The effect of free thermal convection in the epicardiumambient and electrode-ambient interfaces was taken into account using a boundary thermal condition based on Newton's cooling law, which uses a convective heat transfer coefficient $\left(h_{\text {EPI-A }}\right)$ of $20 \mathrm{~W} / \mathrm{m}^{2} \mathrm{~K}$. The ambient temperature was considered to be $21^{\circ} \mathrm{C}$. The effect of forced heat convection in the endocardium-blood was likewise taken into account using a thermal transfer coefficient $\left(h_{\mathrm{EN}-\mathrm{B}}\right)$ of $1770 \mathrm{~W} / \mathrm{m}^{2} \mathrm{~K}$ [26]. The blood circulating inside the atrium was considered to be at $36^{\circ} \mathrm{C}$. The initial temperature was $36^{\circ} \mathrm{C}$ for the entire model.

\section{Construction of the Numerical Model}

The dimensions R and Z (see Fig. 2) were calculated by means of a sensitivity analysis in order to avoid boundary effects. A convergence test was performed to obtain the adequate spatial and temporal resolution. The value of the maximal temperature achieved in the tissue $\left(\mathrm{T}_{\max }\right)$ after $60 \mathrm{~s}$ of RF heating was used as a control parameter in these sensitivity and convergence tests.

Spatial resolution was heterogeneous. We used the criterion that the finest zone was always the electrode-tissue interface, since it is known that this zone has the largest voltage gradient and hence the maximum current density value. In the tissue, grid size was increased gradually with distance from the interface. A tentative spatial and temporal resolution was considered first. We then conducted a computer analysis to determine the appropriate values of $\mathrm{R}$ and $\mathrm{Z}$ (see Fig. 2). These simulations were made by increasing the value of the three parameters by equal amounts. When there was a difference of less than $0.5 \%$ between $\mathrm{T}_{\max }$ and the same parameter in the previous simulation, we considered the former values to be adequate. Finally, we performed convergence tests to determine adequate spatial and temporal resolution. Spatial resolution was achieved by refining the mesh near the blade so that $\mathrm{T}_{\max }$ was within $0.5 \%$ of the value obtained from the previous refinement step. With an adequate spatial resolution achieved, we decreased the time step until $\mathrm{T}_{\max }$ was within $0.5 \%$ of the value obtained from the last time step.

RF power was chosen for the study in order to avoid $T_{\max }$ going above $100^{\circ} \mathrm{C}$, since no experimental data have been reported dealing with the thermal and electrical characteristics of tissue above this temperature. We then analyzed the voltage and temperature distributions in the tissue using the $50^{\circ} \mathrm{C}$ isotherm as thermal lesion boundary.

\section{Modeling the RF Ablation Mode}

Three modes of delivering RF power were considered: constant voltage, current and temperature. All the simulations lasted for $60 \mathrm{~s}$. In the constant voltage mode, the electrical potential was fixed on the active electrode a value of $30 \mathrm{~V}$ (root-mean-square value of the RF applied voltage), while the potential in the dispersive electrode was fixed at zero volts. In the constant current mode, a current of $12 \mathrm{~mA}$ was injected into a node of the active, and the same value was drained from a node on the dispersive electrode. Finally, in the constant temperature mode, the value of the electrical voltage on the active electrode was modulated during heating in order to maintain the center of the active electrode at a temperature of $70 \pm 2^{\circ} \mathrm{C}$ (sampled each $5 \mathrm{~s}$ ). This was done by means of a trial-and-error method such as employed by Jain and Wolf [27].

\section{Modeling the Ablation with a Cooled Electrode}

Thermal cooling by the saline circulating (coolant) inside the electrode tip was modeled by means of a boundary thermal condition based on Newton's cooling law, and by considering a pre-cooling period, i.e. a previous period without applying RF power, as is employed clinically [19]. Previous modeling studies on RF cardiac ablation with

Table 1. Characteristics of the Elements Employed in the Computer Modeling (Data from [8, 25])

\begin{tabular}{|c|c|c|c|c|c|c|}
\hline Element & $\sigma_{100 \mathrm{kHz}}(\mathrm{S} / \mathrm{m})$ & $\sigma_{1 \mathrm{MHz}}(\mathbf{S} / \mathbf{m})$ & $\sigma_{10 \mathrm{MHz}}(\mathrm{S} / \mathrm{m})$ & $\rho\left(\mathrm{kg} / \mathrm{m}^{3}\right)$ & $c(\mathbf{J} / \mathbf{k g} \cdot \mathbf{K})$ & $k(\mathbf{W} / \mathbf{m} \cdot \mathbf{K})$ \\
\hline Fat & 0.025 & 0.025 & 0.03 & 900 & 2222 & 0.20 \\
\hline Blood & 0.99 & 0.99 & 0.99 & 1000 & 4180 & 0.54 \\
\hline Electrode & \multicolumn{3}{|c|}{$7.4 \times 10^{6}$} & $8 \times 10^{3}$ & 480 & 15 \\
\hline
\end{tabular}

$\sigma$ : electrical conductivity (at different frequencies and assessed at $36^{\circ} \mathrm{C}$ ); $\rho$ : mass density; $c$ : specific heat; and $k$ : thermal conductivity. 
cooled electrodes had set surface temperature at the coolant temperature (i.e. Dirichlet boundary condition) [28,29]. However, recent results have suggested that the modeling of RF cooled electrodes should consider a boundary condition based on Newton's cooling law rather than a Dirichlet condition [30]. Since the objective of our study was not to assess the effect of the flow rate of the coolant, we assumed a fixed value of $2000 \mathrm{~W} / \mathrm{m}^{2} \mathrm{~K}$ and a coolant temperature value of $20^{\circ} \mathrm{C}$. In the cooled electrode, we modeled a constant voltage ablation by using the above described electrical boundary conditions.

\section{RESULTS}

\section{Construction of the Model}

Optimum outer dimensions were $\mathrm{R}=\mathrm{Z}=30 \mathrm{~mm}$. The convergence test provided a grid size of $0.075 \mathrm{~mm}$ in the finest zone (fat-active electrode interface), and a step time of $0.5 \mathrm{~s}$ during the first $10 \mathrm{~s}$ and $1 \mathrm{~s}$ for the remaining time. We also checked the grid size away from the electrode. The finite-element model had nearly 4042 nodes and used over 7754 triangular elements.

Table 2. Effect of Frequency and Thickness of Fat Layer on Lesion Geometry and Maximal Temperature ( $\left.T_{\max }\right)$ at a Constant Voltage of $30 \mathrm{~V}$ for $60 \mathrm{~s}$

\begin{tabular}{|c|c|c|c|c|c|c|}
\hline Frequency $(\mathbf{k H z})$ & $\mathbf{F}(\mathbf{m m})$ & $\mathbf{T}_{\max }\left({ }^{\circ} \mathbf{C}\right)$ & D $(\mathbf{m m})$ & $\mathbf{W}(\mathbf{m m})$ & $\mathrm{D}_{\mathrm{FAT}}(\%)$ & $\mathrm{D}_{\mathrm{A}}(\%)$ \\
\hline \multirow{3}{*}{100} & 3 & 65.23 & 2.99 & 6.06 & 99.53 & 0 \\
\hline & 4 & 60.54 & 3.33 & 5.80 & 83.32 & 0 \\
\hline & 5 & 57.77 & 3.36 & 5.12 & 67.14 & 0 \\
\hline \multirow{3}{*}{1000} & 3 & 66.71 & 2.99 & 6.25 & 99.77 & 0 \\
\hline & 4 & 61.23 & 3.40 & 5.85 & 85.05 & 0 \\
\hline & 5 & 58.17 & 3.37 & 5.49 & 67.38 & 0 \\
\hline 10,000 & 2 & 92.59 & 3.46 & 6.99 & 100 & 48.77 \\
\hline
\end{tabular}

F: Epicardial fat layer thickness, D: lesion depth, W: lesion width, $\mathrm{D}_{\mathrm{FAT}}$ : Lesion depth in fat expressed as percentage of fat thickness, $\mathrm{D}_{\mathrm{A}}$ : Lesion depth in atrial tissue expressed as percentage of atrium thickness $(3 \mathrm{~mm})$.

Table 3. Effect of Frequency and Fat Thickness on Lesion Geometry and Maximal Temperature ( $T_{\max }$ ) at a Constant Temperature of $70^{\circ} \mathrm{C}$ for $60 \mathrm{~s}$

\begin{tabular}{|c|c|c|c|c|c|c|}
\hline Frequency $(\mathrm{kHz})$ & $\mathbf{F}(\mathbf{m m})$ & $\mathbf{T}_{\max }\left({ }^{\circ} \mathbf{C}\right)$ & D $(\mathbf{m m})$ & $\mathbf{W}(\mathbf{m m})$ & $\mathrm{D}_{\mathrm{FAT}}(\%)$ & $\mathbf{D}_{\mathrm{A}}(\%)$ \\
\hline \multirow{3}{*}{100} & 2 & 69.34 & 3.15 & 6.30 & 100 & 38.30 \\
\hline & 4 & 69.92 & 3.87 & 7.62 & 96.83 & 0 \\
\hline & 5 & 69.89 & 4.42 & 7.66 & 88.30 & 0 \\
\hline \multirow{3}{*}{1000} & 3 & 70.66 & 3.18 & 7.09 & 100 & 5.87 \\
\hline & 4 & 69.82 & 3.85 & 7.54 & 96.13 & 0 \\
\hline & 5 & 69.11 & 4.38 & 7.74 & 87.68 & 0 \\
\hline \multirow{2}{*}{10,000} & 2 & 70.41 & 3.10 & 6.32 & 100 & 36.73 \\
\hline & 5 & 69.15 & 4.50 & 7.81 & 89.90 & 0 \\
\hline
\end{tabular}

F: Epicardial fat layer thickness, D: lesion depth, W: lesion width, $\mathrm{D}_{\mathrm{FAT}}$ : Lesion depth in fat expressed as percentage of fat thickness, $\mathrm{D}_{\mathrm{A}}$ : Lesion depth in atrial tissue expressed as percentage of atrium thickness $(3 \mathrm{~mm})$. 
Table 4. Effect of Frequency and Fat Thickness on Lesion Geometry and Maximal Temperature ( $\left.T_{\max }\right)$ at a Constant Current of $12 \mathrm{~mA}$ for $60 \mathrm{~s}$

\begin{tabular}{|c|c|c|c|c|c|c|}
\hline Frequency $(\mathbf{k H z})$ & $\mathbf{F}(\mathbf{m m})$ & $\mathbf{T}_{\max }\left({ }^{\circ} \mathbf{C}\right)$ & $\mathbf{D}(\mathbf{m m})$ & $\mathbf{W}(\mathbf{m m})$ & $\mathrm{D}_{\mathrm{FAT}}(\%)$ & $\mathrm{D}_{\mathrm{A}}(\%)$ \\
\hline \multirow{2}{*}{100} & 4 & 81.71 & 3.88 & 7.76 & 96.98 & 0 \\
\hline & 5 & 82.24 & 4.43 & 8.10 & 88.68 & 0 \\
\hline \multirow{3}{*}{1000} & 3 & 79.44 & 3.42 & 6.94 & 100 & 14.13 \\
\hline & 4 & 81.85 & 3.95 & 7.59 & 98.65 & 0 \\
\hline & 5 & 82.32 & 4.55 & 8.08 & 90.90 & 0 \\
\hline \multirow{2}{*}{10,000} & 2 & 70.80 & 2.75 & 5.71 & 100 & 25.10 \\
\hline & 5 & 82.36 & 4.53 & 8.13 & 90.62 & 0 \\
\hline
\end{tabular}

F: Epicardial fat layer thickness, D: lesion depth, W: lesion width, $\mathrm{D}_{\mathrm{FAT}}$ : Lesion depth in fat expressed as percentage of fat thickness, $\mathrm{D}_{\mathrm{A}}$ : Lesion depth in atrial tissue expressed as percentage of atrium thickness $(3 \mathrm{~mm})$.

\section{Effect of Frequency for the Dry Electrode Case}

Tables 2 to 4 show the results of the computer simulations for the dry electrode and for three modes of controlling RF power (constant voltage, temperature and current) when frequency is changed between $100 \mathrm{kHz}$ and 10 MHz. In the case of constant voltage (see Table 2), we observed that the increase of frequency involved higher $T_{\max }$. Moreover, this behavior was more noticeable for a thinner atrial wall: $\mathrm{T}_{\max }$ increased from 76.91 to $92.59^{\circ} \mathrm{C}$ when frequency augmented from $100 \mathrm{kHz}$ to $10 \mathrm{MHz}$ for the case of a $2 \mathrm{~mm}$ thin fat layer, while it increased from 57.77 to $63.19^{\circ} \mathrm{C}$ for the same frequency augmentation in the presence of a $5 \mathrm{~mm}$ thick fat layer. Unfortunately, this increase in $\mathrm{T}_{\max }$ did not involve a significant increase in lesion depth. For instance, the percentage of ablated atrial wall increased from $39.20 \%$ to $48.77 \%$ when frequency increased from $100 \mathrm{kHz}$ to $10 \mathrm{MHz}$ (with $2 \mathrm{~mm}$ of fat). With thicker epicardial fat layers $(4-5 \mathrm{~mm})$, ablation of the atrial wall was not possible. In fact, at a constant voltage, increasing fat thickness involved a decrease in $\mathrm{T}_{\max }$ and in the depth of the lesion in the atrial wall (see Fig. 3A). In the simulations using constant temperature (see Table 3), the results show that increasing frequency hardly involves any variation in either lesion depth in the atrial wall or $\mathrm{T}_{\max }$. In fact, the tiny differences reported in Table $\mathbf{3}$ were probably due to the trial-and-error method employed to simulate the constant temperature protocol of $70 \pm 2^{\circ} \mathrm{C}$ at the electrode tip. Fig. (3B) shows (for $100 \mathrm{kHz}$ ) that even though fat thickness is increased, the temperature distribution remains unaltered, and hence the percentage of ablated atrial tissue is lower for thicker fat layers. Finally, the constant current ablation showed that changing frequency did not affect $\mathrm{T}_{\max }$ (see Table 4). However, a very interesting thermal performance was observed regarding the variation of fat thickness: augmenting fat thickness was directly related to an increase of $\mathrm{T}_{\max }$ from $\approx 70$ to $82^{\circ} \mathrm{C}$ (see Fig. $3 \mathrm{C}$ ). On the other hand, lesion depth in the atrial wall was greater for thinner fat layers.

(A)

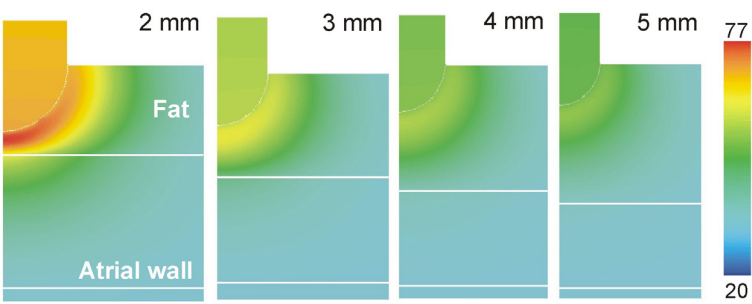

(B)
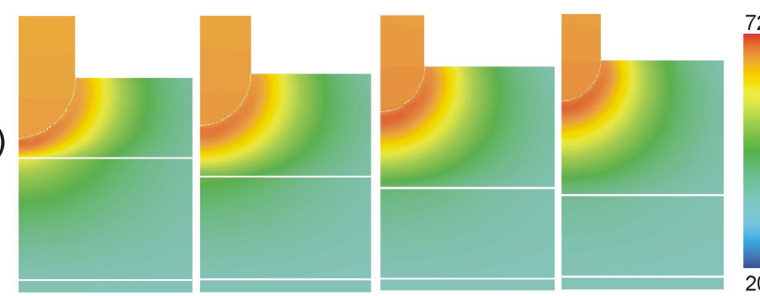

(C)
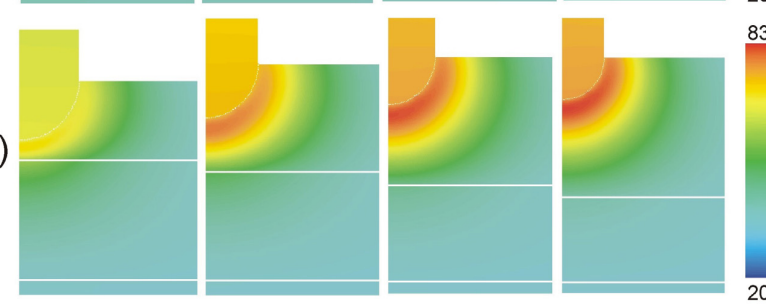

Fig. (3) Temperature distributions at $60 \mathrm{~s}$ for the three modes of delivering RF power: (A) constant $30 \mathrm{~V}$ voltage, (B) constant $70^{\circ} \mathrm{C}$ temperature, (C) constant $12 \mathrm{~mA}$ current; and four values of epicardial fat thickness $(2,3,4$ and $5 \mathrm{~mm})$. All the plots are for the case of $100 \mathrm{kHz}$ frequency. 
Table 5. Effect of Frequency and Fat Thickness on Lesion Geometry and Maximal Temperature ( $\left.T_{\text {max }}\right)$ Using an RF Cooled Electrode and $38 \mathrm{~V}$ for $60 \mathrm{~s}$

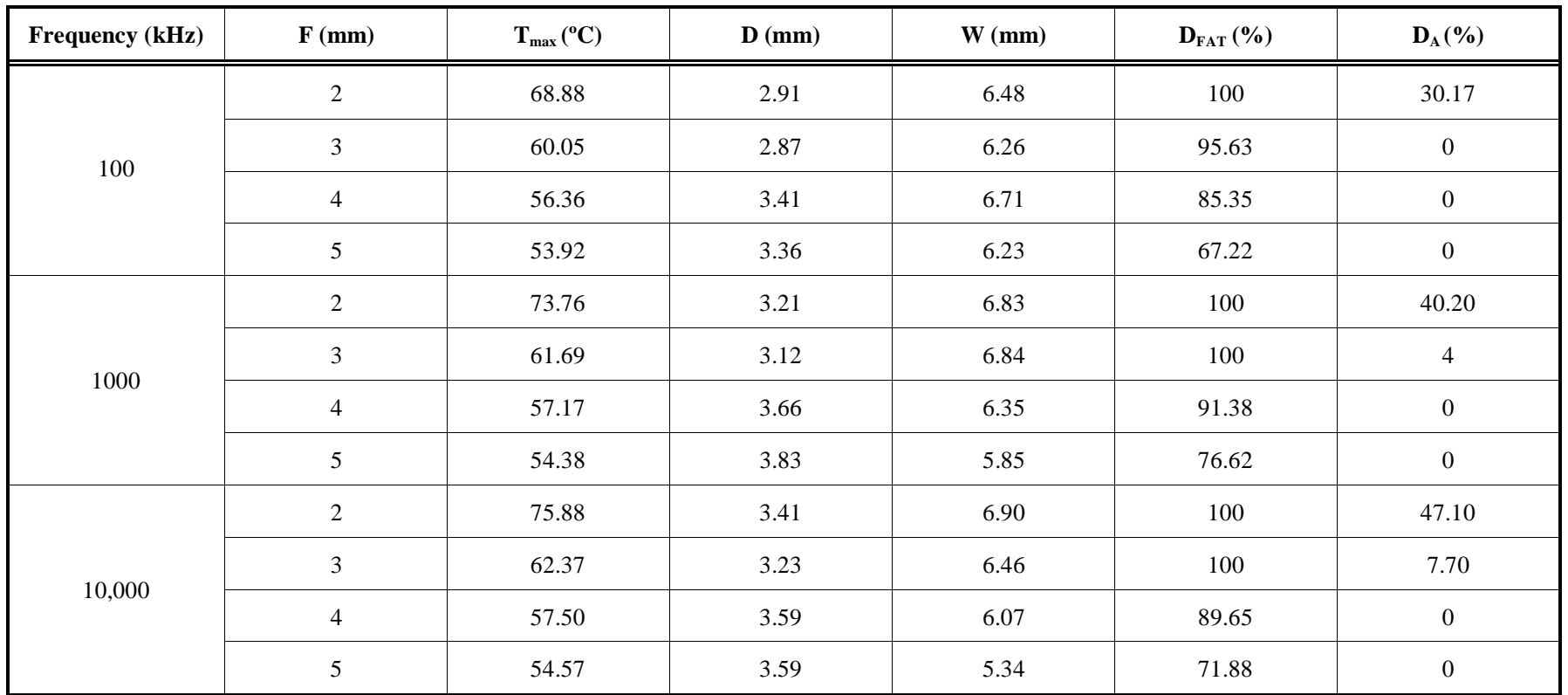

F: Epicardial fat layer thickness, D: lesion depth, W: lesion width, $\mathrm{D}_{\mathrm{FAT}}$ : Lesion depth in fat expressed as percentage of fat thickness, $\mathrm{D}_{\mathrm{A}}$ : Lesion depth in atrial tissue expressed as percentage of atrium thickness $(3 \mathrm{~mm})$.

\section{Ablation with Cooled Electrode}

The results of the simulations using a cooled electrode are shown in Table 5. With this type of electrode and a $2 \mathrm{~mm}$ fat layer, augmenting frequency from $100 \mathrm{kHz}$ to $10 \mathrm{MHz}$ involved a significant increase in the depth of the lesion in the atrial wall, from $30.17 \%$ to $47.10 \%$, and a moderate increase of $\mathrm{T}_{\max }$ (from 68.88 to $75.88^{\circ} \mathrm{C}$ ). Regarding the thermal behavior and thickness of the fat layer, the results were similar to those found for the dry electrode with constant voltage: both $\mathrm{T}_{\max }$ and depth lesion decreased as fat thickness increased (Fig. 4).

\section{Comparison Between Ablation Techniques}

Fig. (5) shows the results of computer simulations for the cases of fat thickness of 2 and $3 \mathrm{~mm}$ (atrial lesions were only observed in these cases and hence are used for comparison). The effect of frequency on atrial lesion depth was more marked in the cooled than dry electrodes (especially for thin fat layers of $2 \mathrm{~mm}$ ). This effect was less marked at constant voltage. When temperature and current were constant, performance was less predictable (especially when we compared the cases 2 and $3 \mathrm{~mm}$ fat thickness). The effect of frequency on $\mathrm{T}_{\max }$ was only noticeable in the case of constant voltage. In the other ablation modes and with a cooled electrode, $\mathrm{T}_{\max }$ kept relatively constant with changes in frequency.

\section{DISCUSSION}

The computer simulations in general showed the difficulty of ablating thick fat layers, as has been previously reported for the case of constant voltage [8]. In this study we assessed other modes of delivering RF power (constant temperature and current), along with the performance of a cooled electrode, and the effect of changing frequency.

The effect of frequency on $T_{\max }$ and lesion depth in the case of constant voltage can be easily explained. Raising the

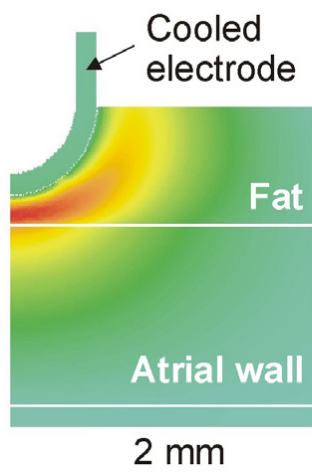

$2 \mathrm{~mm}$

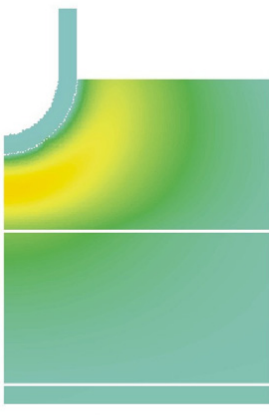

$3 \mathrm{~mm}$

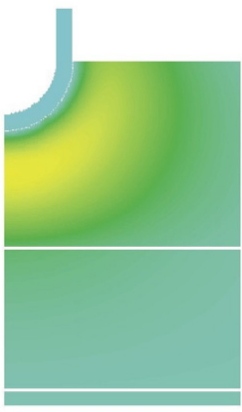

$4 \mathrm{~mm}$

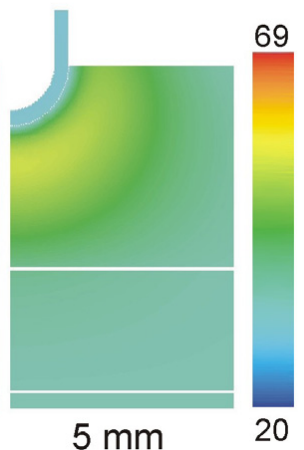

$5 \mathrm{~mm}$
69

Fig. (4). Temperature distributions at $60 \mathrm{~s}$ for RF ablation using a cooled electrode (38 V) and for four values of epicardial fat thickness (2, 3 , 4 and $5 \mathrm{~mm}$ ). All the plots belong to the $100 \mathrm{kHz}$ frequency case. 

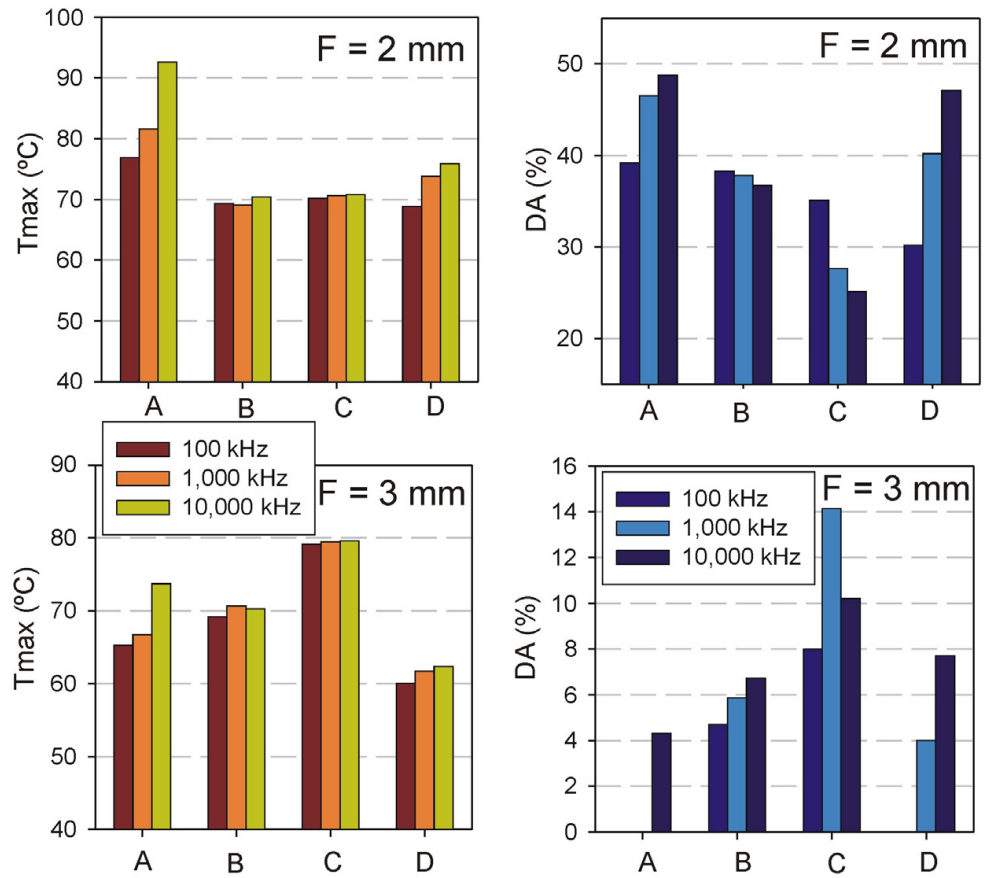

Fig. (5). Maximal temperature (in ${ }^{\circ} \mathrm{C}$ ) (left) and lesion depth in the atrial wall DA (\% atrial wall thickness) (right) at $60 \mathrm{~s}$ for RF ablation using a dry electrode with different protocols: $30 \mathrm{~V}$ constant voltage $(\mathbf{A}), 70^{\circ} \mathrm{C}$ constant temperature $(\mathbf{B}), 12 \mathrm{~mA}$ constant current $(\mathbf{C})$. (D) belongs to RF ablation using a cooled electrode and $38 \mathrm{~V}$ constant voltage. The figure also shows the results of three different frequencies: $100 \mathrm{kHz}, 1 \mathrm{MHz}$ and $10 \mathrm{MHz}$. The top plots belong to the case of $2 \mathrm{~mm}$ epicardial fat thickness and those at the bottom to the case of $3 \mathrm{~mm}$ epicardial fat thickness.

frequency involves an increase in electrical conductivity $(\sigma)$ of the atrial tissue (from 0.21 to $0.6 \mathrm{~S} / \mathrm{m}$ ), which means that more current will be delivered, and hence more power will be applied. Moreover, since the $\sigma$ of the fat remains almost unaffected when frequency rises, this explains why the effect is more marked with thinner fat layers. Our results do not demonstrate that it is impossible to ablate atrial wall with constant voltage for fat layers over $4 \mathrm{~mm}$. In fact, as shown in Table 2, the application of $30 \mathrm{~V}$ for the case of a $5 \mathrm{~mm}$ fat layer and $10 \mathrm{MHz}$, only involves a $\mathrm{T}_{\max }$ of $63.19^{\circ} \mathrm{C}$, which means that higher voltage could be applied in order to increase lesion depth. As a consequence, and as is already known, each combination of electrode design and tissue characteristics determines the optimum combination of voltage and duration to enlarge the lesion without reaching $100^{\circ} \mathrm{C}$. Our results with constant voltage therefore only show the trend of $T_{\max }$ and lesion depth when frequency is raised for different fat thicknesses. This trend can be summarized as follows: 1) Increasing fat thickness implies a decrease in $\mathrm{T}_{\max }$ and also in the depth of the lesion in the atrial wall, and 2) Increasing frequency involves higher $T_{\max }$ and deeper lesions in the atrial wall, and additionally this increase is more noticeable when the atrial wall is thin. The results suggest that constant voltage is not a safe ablation method on the epicardial fat layer, since fat thickness is generally unknown and it is thus difficult to set a voltage value to achieve a lesion in the atrial wall and at the same time avoid excessive $\left(\approx 100^{\circ} \mathrm{C}\right)$ temperatures in the fat and atrial wall tissue. In contrast, ablating at a constant temperature provides safer heating, i.e. without excessive temperatures $\left(\approx 100^{\circ} \mathrm{C}\right)$, regardless of fat thickness. The obvious drawback is that when the fat layer is very thick $(4-5 \mathrm{~mm})$ it is nearly impossible to reach the atrial wall (see Fig. 3B). In the constant current ablation we observed that the value of $\mathrm{T}_{\max }$ was almost independent of the frequency. This can be explained as follows: on one hand, the electrical conductivity of fat $\left(\sigma_{F A T}\right)$ was not influenced by frequency (see Table $\mathbf{1}$ ), and on the other hand, electrical power was deposited within a very small zone around the active electrode (corresponding always to fat). Under these circumstances, $\mathrm{T}_{\max }$ was somehow proportional to $\sigma_{F A T} \cdot|E|^{2}$, or equally $|J|^{2} / \sigma_{F A T}$. Since both the injected current $(I)$ and contact surface $(S)$ between electrode and tissue were constant, the value of $J$ $(=I / S)$ at the electrode-fat interface was also constant, and this could hence explain this behavior of $\mathrm{T}_{\max }$. Additionally, we observed that increasing fat thickness was directly related to an increase of $\mathrm{T}_{\max }$ (see Fig. 3C). It seems that the change of the atrial tissue's $\sigma_{\mathrm{A}}$ (due to the different frequency) does not sufficiently affect the value of the total impedance of the tissue $\left(\mathrm{Z}_{\text {TОтАL }}\right)$, probably because the current density is low in this zone. However, increasing fat thickness (with $\left.\sigma_{\mathrm{A}}>\sigma_{\mathrm{FAT}}\right)$ does cause a rise in $\mathrm{Z}_{\mathrm{TOTAL}}$, and this implies an increase in the total delivered power $\left(I^{2} \cdot \mathrm{Z}_{\mathrm{TOTAL}}\right)$, which could raise the value of $T_{\max }$. This thermal behavior could be employed as a self-controlling procedure to ablate a thick layer of epicardial fat: at the beginning, when the layer is thick the current would create a high temperature which could melt the fat and reduce its thickness. During this process the total applied power would be reduced. 
A study was also made of the performance of the cooled electrode. In this case, we observed that for $2 \mathrm{~mm}$ fat thickness, raising the frequency did involve a considerable increase in the depth of the lesion in the atrial wall. We are of the opinion that this is due to the location of $\mathrm{T}_{\max }$ being shifted towards deeper points by the cooling effect, i.e. in our case (thin fat layer) towards the atrial tissue, where electrical conductivity increases as frequency is higher. The rise in the electrical conductivity of the atrial tissue implies an increase in the RF deposited power, and hence in $\mathrm{T}_{\max }$.

In our study we only considered an electrode size of 4 $\mathrm{mm}$. Despite that it is known that the electrode length affects on the lesion dimensions in RF cardiac ablation, this is particularly true for endocardial approach, where the forced thermal convection caused by cooling blood on the electrode surface has a strong impact in tissue heat removing, and hence on the lesion depth. In contrast, since we modeled an epicardial approach, and under this condition there is not circulating blood around the electrode, we did not consider simulations for other electrode length. Regarding the electrode diameter, we only considered a value of $3 \mathrm{~mm}$, which is about a 7 Fr electrode. We think that the effect of increasing this parameter has different effect depending on the ablation protocol (constant temperature, voltage and current) and on the electrode type (dry vs. cooled), due to the change in diameter implies a change in tissue impedance as well. Likewise, the change in insertion depth also implies a change in the tissue impedance. Additional considering a larger diameter electrode could produce different results quantitatively different to ours (both in lesion dimension and $\mathrm{T}_{\max }$ ), however, we think that the general conclusions (see below) remain unaltered. Likewise, other factors, such as the angle between tissue surface and electrode axis, and the convective cooling coefficient at endocardium-blood interface, could showed different results, but they were not considered in our study since that they have been previously characterized $[8,31]$.

Since that our results suggest that RF ablation is clearly disadvantageous to ablate cardiac tissue in the presence of epicardial fat layer, other ablation modalities such as High Intensity Focused Ultrasound (HIFU), microwave or cryoablation, could be potentially more useful. In this respect, the lower value of attenuation of fat $(\approx 6 \mathrm{~dB} / \mathrm{m} \cdot \mathrm{MHz})$ versus cardiac tissue $(35-70 \mathrm{~dB} / \mathrm{m} \cdot \mathrm{MHz})$ could be useful, along with the capability of microwave power of reaching deeper tissue sites. In contrast, the lower value of thermal conductivity of fat $(0.2 \mathrm{~W} / \mathrm{m} \cdot \mathrm{K})$ versus cardiac tissue $(0.7$ $\mathrm{W} / \mathrm{m} \cdot \mathrm{K}$ ) does not suggest an advantage of thermal therapies exclusively based on thermal conduction, such as cryoablation.

\section{CONCLUSIONS}

1) The effect of increasing frequency on atrial lesion depth was more marked in the case of cooled electrodes than in dry electrodes, especially for thin fat layers $(2 \mathrm{~mm})$.

2) With dry electrodes, increasing frequency had little influence on atrial lesion depth in the case of constant voltage. In the cases of constant temperature and current, the performance was less predictable (especially with thick fat layers).
3) The effect of frequency on $T_{\max }$ was only noticeable in the case of constant voltage. In the other ablation modes with a cooled electrode $\mathrm{T}_{\max }$ stayed relatively constant when frequency was altered.

4) In general, our computer results suggest that RF ablation of the atrial wall with overlying epicardial fat is difficult due to the marked difference in electrical conductivity between fat $(0.025 \mathrm{~S} / \mathrm{m})$ and muscle $(\approx 0.4 \mathrm{~S} / \mathrm{m})$. The epicardial fat layer seriously impedes the passage of RF current, thus reducing the effectiveness of atrial wall ablation.

\section{ACKNOWLEDGMENTS}

This work was supported by a research grant from the Spanish Government in the "Plan Nacional de I+D+I del Ministerio de Ciencia e Innovación" (TEC2008-01369/TEC). We would like to thank the $\mathrm{R}+\mathrm{D}+\mathrm{i}$ Linguistic Assistance Office at the Universidad Politécnica of Valencia for their help in revising this paper.

\section{REFERENCES}

[1] W. B. Kannel, P. A. Wolf, E. J. Benjamin, and D. Levy, "Prevalence, incidence, prognosis, and predisposing conditions for atrial fibrillation: population-based estimates", Am. J. Cardiol., vol. 82, pp. 2N-9N, Oct. 1998.

[2] E. J. Benjamin, D. Levy, S. M. Vaziri, R. B. D'Agostino, A. J. Belanger, and P. A. Wolf, "Independent risk factors for atrial fibrillation in a population-based cohort. The Framingham Heart Study", JAMA, vol. 271, no. 11, pp. 840-844, Mar. 1994.

[3] P.A. Wolf, R.D. Abbott, and W.B. Kannel, "Atrial fibrillation as an independent risk factor for stroke: the Framingham Study”, Stroke, vol. 22, pp. 983-988, Aug. 1991.

[4] K. Khargi, B. A. Hutten, B. Lemke, and T. Deneke, "Surgical treatment of atrial fibrillation; a systematic review", Eur. J. Cardiothorac. Surg., vol. 27, pp. 258-265, Feb. 2005.

[5] J. L. Cox, R. B. Schuessler, D. G. Lappas, and J. P. Boineau, “An 8 1/2-year clinical experience with surgery for atrial fibrillation", Ann. Surg., vol. 224, pp. 267-273, Sep. 1996.

[6] H. Nakajima, J. Kobayashi, K. Bando, K. Niwaya, O. Tagusari, Y. Sasako, T. Nakatani, and S. Kitamura, "The effect of cryo-maze procedure on early and intermediate term outcome in mitral valve disease: case matched study", Circulation, vol. 106, pp. I46-I50, Sep. 2002.

[7] Y. Miyagi, Y. Ishii, T. Nitta, M. Ochi, and K. Shimizu, "Electrophysiological and histological assessment of transmurality after epicardial ablation using unipolar radiofrequency energy", $J$. Card. Surg., vol. 24, no. 1, pp. 34-40, Jan.-Feb. 2009.

[8] E. J. Berjano, and F. Hornero, "Thermal-electrical modeling for epicardial atrial radiofrequency ablation", IEEE Trans. Biomed. Eng., vol. 51, no. 8, pp. 1348-1357, Aug. 2004.

[9] T. Santiago, J. Q. Melo, R. H. Gouveia, and A. P. Martins, "Intraatrial temperatures in radiofrequency endocardial ablation: histologic evaluation of lesions", Ann. Thorac. Surg., vol. 75, pp. 1495-1501, May 2003.

[10] T. Santiago, J. Melo, R. H. Gouveia, L. M. Abecasis, P. Adragão, and A. P. Martins, "Epicardial radiofrequency applications: in vitro and in vivo studies on human atrial myocardium", Eur. J. Cardiothorac. Surg., vol. 24, pp. 481-486, Oct. 2003.

[11] T. Deneke, K. Khargi, K. M. Müller, B. Lemke, A. Mügue, A. Laczkovics, A. E. Becker, and P. H. Grewe, "Histopathology of intraoperatively induced linear radiofrequency ablation lesions in patients with chronic atrial fibrillation", Eur. Heart J., vol. 26, pp. 1797-1803, Sep. 2005.

[12] K. N. Hong, M. J. Russo, E. A. Liberman, A. Trzebucki, M. C. Oz, M. Argenziano, M. R. Williams, "Effect of epicardial fat on ablation performance: a three-energy source comparison", J. Card. Surg., vol. 22, no. 6, pp. 521-524, Nov.-Dec. 2007.

[13] S. P. Thomas, D. J. Guy, A. C. Boyd, V. E. Eipper, D. L. Ross, and R. B. Chard, "Comparison of epicardial and endocardial linear ablation using handheld probes," Ann. Thorac. Surg., vol. 75, pp. 543-548, Feb. 2003. 
[14] S. Mitnovetski, A. A. Almeida, J. Goldstein, A. W. Pick, and J. A. Smith, "Epicardial high-intensity focused ultrasound cardiac ablation for surgical treatment of atrial fibrillation", Heart Lung Circ., vol. 18, no. 1, pp. 28-31, Feb. 2009.

[15] J. C. Pruitt, R. R. Lazzara, and G. Ebra, "Minimally invasive surgical ablation of atrial fibrillation: The thoracoscopic box lesion approach", J. Interv. Card. Electrophysiol., vol. 20, no. 3, pp. 8387, Dec. 2007

[16] M. Ba, P. Fornés, O. Nutu, C. Latrémouille, A. Carpentier, and J. C. Chachques, "Treatment of atrial fibrillation by surgical epicardial ablation: bipolar radiofrequency versus cryoablation", Arch. Cardiovasc. Dis., vol. 101, no. 11-12, pp. 763-768, Nov.Dec. 2008.

[17] E. J. Berjano, "Theoretical modeling for radiofrequency ablation: state-of-the-art and challenges for the future", Biomed. Eng. Online, vol. 5, p. 24, Apr. 2006

[18] P. Koovor, V. E. Eipper, B. I. Dewsnap, S. McKinley, H. T. Nguyen, J. B. Uther, and D. L. Ross, "The effect of different frequencies on lesion size during radiofrequency ablation", Circulation, vol. 94, p. I-677, 1996.

[19] A. d'Avila, C. Houghtaling, P. Gutierrez, O. Vragovic, J. N. Ruskin, M. E. Josephson, and V. Y. Reddy, "Catheter ablation of ventricular epicardial tissue: a comparison of standard and cooledtip radiofrequency energy", Circulation, vol. 109, no. 19, pp. 23632369, May 2004.

[20] J. S. Raman, S. Ishikawa, and J. M. Power, "Epicardial radiofrequency ablation of both atria in the treatment of atrial fibrillation: Experience in patients," Ann. Thorac. Surg., vol. 74, no. 5, pp. 1506-1509, Nov. 2002.

[21] D. E. Haines, and D. D. Watson, "Tissue heating during radiofrequency catheter ablation: a thermodynamic model and observations in isolated perfused and superfused canine right ventricular free wall", Pacing Clin. Electrophysiol., vol. 12, no. 6, pp. 962-976, Jun. 1989.

[22] J.A. Pearce, Electrosurgery. Cambridge: Chapman and Hall, 1986, pp. 224-234.

[23] J. D. Doss, "Calculation of electric fields in conductive media", Med. Phys., vol. 9, pp. 566-573, Jul.-Aug. 1982.
[24] D. Haemmerich, and B. J. Wood, "Hepatic radiofrequency ablation at low frequencies preferentially heats tumour tissue", Int. J. Hyperthermia, vol. 22, no. 7, pp. 563-574, Nov. 2006.

[25] S. Gabriel , R. W. Lau, and C. Gabriel, "The dielectric properties of biological tissues: III. Parametric models for the dielectric spectrum of tissues", Phys. Med. Biol., vol. 41, no. 11, pp. 22712293, Nov. 1996.

[26] D. Schutt, E. J. Berjano, and D. Haemmerich, "Effect of electrode thermal conductivity in cardiac radiofrequency catheter ablation: A computational modeling study", Int. J Hyperthermia., vol. 25, no. 2, pp. 99-107, March 2009.

[27] M. K. Jain, and P. D. Wolf, "Temperature-controlled and constantpower radio-freqiency ablation: what affects lesion growth?", IEEE Trans. Biomed. Eng., vol. 46, no. 12, pp. 1405-1412, Dec. 1999.

[28] M. K. Jain, P. D. Wolf, and C. Henriquez, "Chilled-tip electrode radio frequency ablation of the endocardium: a finite element study", in Proceedings of the 17th Annual Conference of the IEEE Engineering in Medicine and Biology Society (IEEE-EMBS), 1995, pp. 273-274.

[29] D. Panescu, S. D. Fleischman, J. G. Whayne and D. K. Swanson, "Temperature distribution under cooled electrodes during radiofrequency catheter ablation", In Proceedings of the 17th Annual Conference of the IEEE Engineering in Medicine and Biology Society (IEEE-EMBS), 1995, pp. 299-300.

[30] M. J. Rivera, J. A. López Molina, M. Trujillo, E. J. Berjano, "Theoretical modeling of RF ablation with internally cooled electrodes: comparative study of different thermal boundary conditions at the electrode-tissue interface", Math. Biosci. Eng. vol. 6 , no. 3, pp. 611-27, 2009.

[31] D. Panescu, J. G. Whayne, S. D. Fleishman, M. S. Mirotznik, D. K. Swanson, and J. G. Webster, "Three-dimensional finite element analysis of current density and temperature distributions during radio-frequency ablation", IEEE Trans. Biomed. Eng., vol. 42, no. 9, pp. 879-890, Sep. 1995 